\title{
Reconciling roles of sulphate aerosol forcing and internal variability in Atlantic multidecadal climate changes
}

\author{
Masahiro Watanabe $^{1}$ (D) Hiroaki Tatebe $^{2}$
}

Received: 24 November 2018 / Accepted: 8 May 2019 / Published online: 13 May 2019

(c) The Author(s) 2019

\begin{abstract}
The interdecadal basin-wide warming and cooling cycle of the North Atlantic Ocean, known as the Atlantic multidecadal variability (AMV), influences not only the Euro-Atlantic climatic conditions, but also tropical storms and monsoons remotely. However, controversy still remains on the relative importance of external forcing and internal processes for the past AMV. Here, we use three attribution experiments, consisting of five-member ensemble for each, for 1931-2014 by a climate model and show that the temporal variation of the observed AMV can be reproduced in the model forced by historical changes in radiative forcing. Specifically, anthropogenic sulphate emissions are found to explain 46-63\% of the forced SST variations at decadal time scales. The spatial pattern of the sea surface temperature (SST) associated with the AMV is also well captured by the model, in which externally forced components dominate and significantly increase precipitation over Europe and the Sahel during positive AMV. An exception is the subpolar region where internally generated SST variability coupled with the North Atlantic Oscillation plays a major role. Under declining scenarios of anthropogenic aerosol emissions, a multi-model ensemble of climate simulations shows that the North Atlantic decadal SST variability will be generated increasingly by internal processes, suggesting a decreasing impact on regional precipitation.
\end{abstract}

Keywords Atlantic multidecadal variability $\cdot$ Sulphate aerosols $\cdot$ Climate model

\section{Introduction}

Past SST changes in the North Atlantic basin, which have revealed a secular warming trend imposed on a multidecadal variability (Schlesinger and Ramankutty 1994; Kushnir 1994), have been in step with the global mean surface temperature and has been called the 'pacemaker' of global warming (Kerr 2000). Multidecadal SST variability, aka $\mathrm{AMV}$, tends to show a uniform sign of anomalies in the basin, which has turned to a positive phase since the middle of 1990s and affected temperature and precipitation patterns across Europe (Sutton and Hodson 2005; Sutton and Dong 2012). The influence of the AMV is not confined to

Masahiro Watanabe

hiro@aori.u-tokyo.ac.jp

1 Atmosphere and Ocean Research Institute, The University of Tokyo, 5-1-5 Kashiwanoha, Kashiwa, Chiba 277-8568, Japan

2 Japan Agency for Marine-Earth Science and Technology, 3173-25 Showa-machi, Kanazawa-ku, Yokohama, Kanagawa 236-0001, Japan the Euro-Atlantic sector such as droughts in US (Enfield et al. 2001) and Atlantic hurricanes (Goldenberg et al. 2001; Dunstone et al. 2013), but is observed in remote African and Indian monsoon regions (Folland et al. 1986; Zhang and Delworth 2006; Knight et al. 2006). Therefore, understanding mechanisms of the AMV is crucial for better prediction and adaptation to AMV driven climate changes (Sutton et al. 2018).

The conventional view of the origin of the AMV was an oscillatory mode of low-frequency climate variability coupled with changes in the Atlantic Meridional Overturning Circulation (AMOC) strength (Delworth et al. 1993; Delworth and Mann 2000; Zhang and Wang 2013). The latter has a long 'memory' that may explains the decadal timescale of the AMV, so that North Atlantic SST anomalies can potentially be predicted several years into the future (Keenlyside et al. 2008; Matei et al. 2012). However, this is not a unique explanation of the observed AMV. A recent study showed that the observed AMV pattern is reproduced in a model coupled with a slab ocean, suggesting that the SST pattern per se is a response to stochastic forcing from the atmosphere without coupling to the AMOC (Clement 
et al. 2015). Regarding the decadal time scale as seen in the observed AMV, there is accumulating evidence that the external radiative forcing such as solar activity, ozone, and volcanic and anthropogenic aerosols is an important driver in terms of the variance and the timing of phase changes (Otterå et al. 2010; Booth et al. 2012; Wang et al. 2017; Undorf et al. 2018; Bellomo et al. 2018).

One important study for the above issue was done by Booth et al. (2012), who reproduced the time evolution of the past AMV using a single coupled general circulation model (CGCM) and attributed the substantial fraction of the simulated variance to historical changes in sulphate aerosols. A similar conclusion was obtained from a large ensemble of historical simulations using a different CGCM (Undorf et al. 2018). However, there has been a criticism to the results by Booth et al. (2012). Zhang et al. (2013) pointed out the model errors in reproducing observed ocean heat content changes, an important measure of the forced oceanic response, and thus controversy still remains on the relative importance of external forcing and internal processes for the past AMV. Estimating to what extent the AMV is driven by external forcing has been attempted using Coupled Model Intercomparison Project Phase 5 (CMIP5) multi-model ensembles (Terray 2012; Murphy et al. 2017), but it is difficult to draw conclusions from CMIP5 simulations alone due to lack of precise attribution experiments to date.

Given the above discussion, we reconcile the roles of external forcing due to sulphate aerosols and internal processes in driving the past AMV. Major questions addressed in this study are: (a) whether the criticism by Zhang et al. (2013) is a specific problem with a previous model or reflects a general issue about potential aerosol driving of the AMV, (b) how and where external and internal drivers are important in simulating the past AMV, and (c) whether the future AMV drivers change, and what this means for decadal climate predictions. For the attribution, we perform ensemble historical experiments by a CGCM, in which sulphate aerosol forcing is either prescribed at a pre-industrial condition or varies in time. We will then explore how the relative roles between externally forced and internally generated variations might change under future scenarios using a subset of the CMIP5 initial condition ensembles, and what implications this might have for our ability to predict these future changes.

\section{Model and data}

\subsection{MIROC attribution experiments}

We used the Model for Interdisciplinary Research on Climate version 5.2 (MIROC5.2) CGCM (Watanabe et al. 2014), which is an updated version from our CMIP5 model of MIROC5 (Watanabe et al. 2010). The resolution is T85 spectral truncation (horizontal spacing of approximately $150 \mathrm{~km})$ and 40 vertical levels for the atmosphere, and $1^{\circ}$ and 63 vertical levels for the ocean. MIROC5.2 implements an aerosol model called SPRINTARS (Takemura et al. 2009), which predicts the mass mixing ratio of sulphate aerosols and other major aerosol species, as well as precursor gasses to sulphate. In addition to the direct effect of aerosols on radiative transfer, first- and second-order indirect effects are included in SPRINTARS by considering the dependence of cloud droplet nucleation on the number concentration of aerosol particles. Volcanic sulphate aerosols are presented as aerosol optical depth at four different altitudes in the stratosphere, including seasonal cycle and year-to-year variations. The emission of hydroxyl $(\mathrm{OH})$ radical, precursor to sulphate aerosols, is assumed to be a constant, which may underrepresent the indirect effects, but the resultant long-term observed temperature changes have been reproduced well.

The MIROC5.2 historical experiment (denoted as HIST) driven by all external forcing agents for 1921-2014 was branched off from the official MIROC5 historical experiment, with the external forcing used for the historical experiment before 2005 and for the RCP4.5 run after 2006. Initial conditions for 1 January 1921 have been taken from each of the official five-member historical runs for generating the ensemble in this study, and the initial 10 years of data were discarded for the analysis. Furthermore, two attribution experiments (VOLSO2CONST and SO2CONST, five members for each) were conducted but with sulphate aerosol forcing of either natural volcanic origin or both natural and anthropogenic origins prescribed to their pre-industrial level (Table 1). These runs are a prototype of the CMIP Phase 6 (CMIP6) Detection and Attribution Model Intercomparison Project (DAMIP) experiments (Gillett et al. 2016), and have successfully isolated the impact of sulphate aerosol forcing on the tropical Pacific climate changes over the past eight decades (Takahashi and Watanabe 2016). In this study, we perform a combined analysis of the three ensembles for a quantitative estimate of the contribution of anthropogenic and volcanic sulphate aerosols to the AMV cycles in the twentieth century after 1930.

Table 1 Description of MRIOC5.2 ensemble experiments

\begin{tabular}{llll}
\hline Experiment & $\begin{array}{l}\text { Anthropogenic } \\
\text { sulphate aero- } \\
\text { sol forcing }\end{array}$ & $\begin{array}{l}\text { Natural sul- } \\
\text { phate aerosol } \\
\text { forcing }\end{array}$ & $\begin{array}{l}\text { GHGs and other } \\
\text { radiative forcing }\end{array}$ \\
\hline HIST & Historical & Historical & Historical \\
SO2CONST & Pre-industrial & $\begin{array}{l}\text { Pre-industrial } \\
\text { VOLSO- }\end{array}$ & Historical \\
2CONST & & Pre-industrial & Historical \\
\hline
\end{tabular}




\subsection{CMIP5 initial condition ensemble}

We also analysed historical and RCP4.5 simulations (Taylor et al. 2012) for the period of 1931-2100 from five CMIP5 models (CanESM2, CCSM4, CSIRO-Mk3.6.0, GISSE2-R, and MIROC5), which provide five-member ensembles for separating the internal and external components (see http://cmip-pcmdi.llnl.gov/cmip5/availability.html for more detail). After SST fields were interpolated on a regular $2.5^{\circ} \times 2.5^{\circ}$ grid, we used the two periods for the analysis: 1931-2000 and 2031-2100, from which linear trends were subtracted in advance.

All five models deal with an interaction of sulphate aerosols with radiation (Table 2). Since the atmospheric aerosol concentration is calculated from the surface emission in an aerosol module that accounts for transport, deposition, settling, and sulphur chemistry, the aerosol column loading is different in different models (von Salzen et al. 2013; Neale et al. 2010; Rotstayn et al. 2010; Watanabe et al. 2010; Koch et al. 2011). Three out of five models (CanESM2, CSIROMk3.6.0, and MIROC5) incorporate both direct and indirect effects of the sulphate aerosols.

\subsection{Observational data}

Several observational data sets are used to compare with the simulations: monthly SSTs derived from COBE SST during 1845-2014 and a concurrent ocean temperature dataset for 1945-2014, both having a $1^{\circ}$ horizontal resolution (Ishii and Kimoto 2009), surface air temperature (SAT) and SLP data based on the HadCRUT4 and HadSLP datasets, respectively, for 1850-2012 on a $5^{\circ}$ grid (Morice et al. 2012; Allan and Ansell 2006), and land precipitation data obtained from GPCC version 6 for $1901-2010$ on a $2.5^{\circ}$ grid (Schneider et al. 2013).

\subsection{Analysis methods}

We applied a 10-year low-pass, Lanczos filter to the detrended annual mean anomalies relative to the 1931-1990 mean state for both observations and simulations (for the CMIP5 RCP4.5 runs, anomalies are relative to the 2031-2090 mean). A statistical test for correlation coefficients was performed using a two-sided Student's $t$ test with an estimate of effective sample size for the filtered data. In the CGCM ensemble, external and internal components were defined by the ensemble average and deviations from the ensemble mean. The five-member ensemble may not be large to sufficiently remove the internal component from the ensemble mean where the internal variability is dominant over the forced variability (Kay et al. 2015). As will be shown, fortunately, the Atlantic SST variability at decadal time scales contains a discernible forced component even with this small ensemble.

In the MIROC5.2 ensembles, configuration of the external forcing varies, so that contributions from the volcanic sulphate aerosols can be distinguished by using the differences between HIST and VOLSO2CONST, whereas the difference between VOLSO2CONST and SO2CONST represents contributions from anthropogenic sulphate aerosols (Table 3). Anomalies in SO2CONST represent the contribution of non-radiative boundary effects such as land-use change and all the radiative forcing parameters, excluding sulphate aerosols.

\section{Results of the MIROC attribution experiments}

\subsection{Radiative forcing due to sulphate aerosols}

Anthropogenic $\mathrm{SO}_{2}$ emissions over North America and Europe and the sulphate aerosol optical depth for volcanoes are presented in Fig. 1a. Both show large values during the 1960s and the mid-1990s, when surface solar insolation had decreased compared to other periods (Fig. 1b). The indirect aerosol effect is caused by changes in cloud lifetime and optical depth, and is measured by changes in surface shortwave cloud radiative forcing (Fig. 1b). Local values may largely reflect changes in clouds due to circulation anomalies, but we think that the large-scale average over the North Atlantic represents the indirect aerosol effect. Unlike clearsky shortwave radiation, the cloud radiative effect does not show a large multidecadal variability, but shows a strong positive value (heating) during the recent warm period of the AMV.

Table 2 Treatment of sulphate aerosols in the five CMIP5 models analysed in this study

\begin{tabular}{llll}
\hline Model name & Sulphate aerosol treatment & Radiative effect & References \\
\hline CanESM2 & Interactive, emission to concentration & Direct + semidirect + indirect & von Salzen et al. (2013) \\
CCSM4 & Interactive, emission to concentration & Direct + semidirect & Neale et al. (2010) \\
CSIRO-Mk3.6.0 & Interactive, emission to concentration & Direct + semidirect + indirect & Rotstayn et al. (2010) \\
GISS-E2-R & Semi-interactive, emission to concentration & Direct + semidirect & Koch et al. (2011) \\
MIROC5 & Interactive, emission to concentration & Direct + semidirect +indirect & Watanabe et al. (2010) \\
\hline
\end{tabular}


Table 3 Values of AMV indices, defined as the North Atlantic SST anomalies $\left({ }^{\circ} \mathrm{C}\right)$ with respect to the 1931-1990 mean, for three periods corresponding to positive, negative, and positive phases

\begin{tabular}{llll}
\hline & $1931-1960$ & $1961-1995$ & $1996-2014$ \\
\hline COBE SST & 0.10 & -0.21 & 0.22 \\
MIROC5.2 All & $0.08 \pm 0.01$ & $-0.16 \pm 0.01$ & $0.17 \pm 0.02$ \\
Anthropogenic SO & & $-0.09 \pm 0.04(53 \%)$ & $0.08 \pm 0.05(46 \%)$ \\
Natural SO & $0.05 \pm 0.01(63 \%)$ & $-0.05 \pm 0.02(31 \%)$ & $0.06 \pm 0.02(37 \%)$ \\
Others (incl. GHGs) & $0.02 \pm 0.02(24 \%)$ & $-0.03 \pm 0.03(16 \%)$ & $0.03 \pm 0.04(18 \%)$ \\
\hline
\end{tabular}

The model values (denoted as 'All') are taken from HIST. Contributions due to anthropogenic and natural volcanic sulphate aerosols are calculated using differences between ensembles (VOLSO2CONSTSO2CONST and HIST-VOLSO2CONST) while contribution due to other radiative forcing including greenhouse gasses (GHGs) is obtained from SO2CONST. All values are calculated after removing linear trends. Uncertainty ranges are obtained from the ensemble spread. Fractional contribution to 'All' is also indicated in parentheses

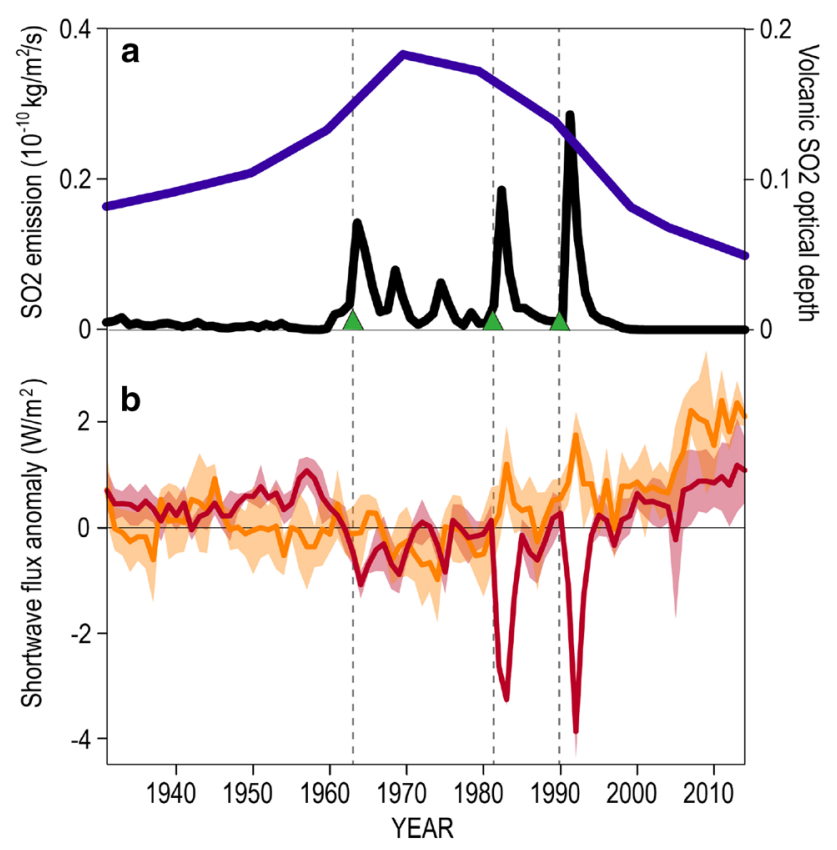

Fig. 1 Time series for 1931-2014 of (a) the global mean sulphate aerosol optical depth due to volcanic emissions (black) and anthropogenic sulphate emissions averaged over North America and Europe (blue) given to MIROC5.2, (b) surface clear-sky (red) and cloud (orange) net shortwave radiation obtained from HIST. Radiation data are annual mean anomalies relative to the 1931-1990 mean and averaged over the North Atlantic Ocean. Solid curve and shading indicate the ensemble mean anomaly and the ensemble spread, respectively. Green triangles with vertical dashed lines represent three major volcanic eruptions (Agung, El Chichón, and Pinatubo)

\subsection{Sulphate aerosol driving of the AMV}

Figure 2 compares the observed and simulated time series of the AMV index defined as the spatial average of annualmean detrended SST anomalies in the North Atlantic between $0^{\circ}-70^{\circ} \mathrm{N}$ and longitudes of $80^{\circ} \mathrm{W}-0^{\circ}$ (Mahajan et al. 2011; see box in Fig. 3a). It is evident that HIST captures the cooling period between the 1960s and the early 1990s as well as the warming periods before and after

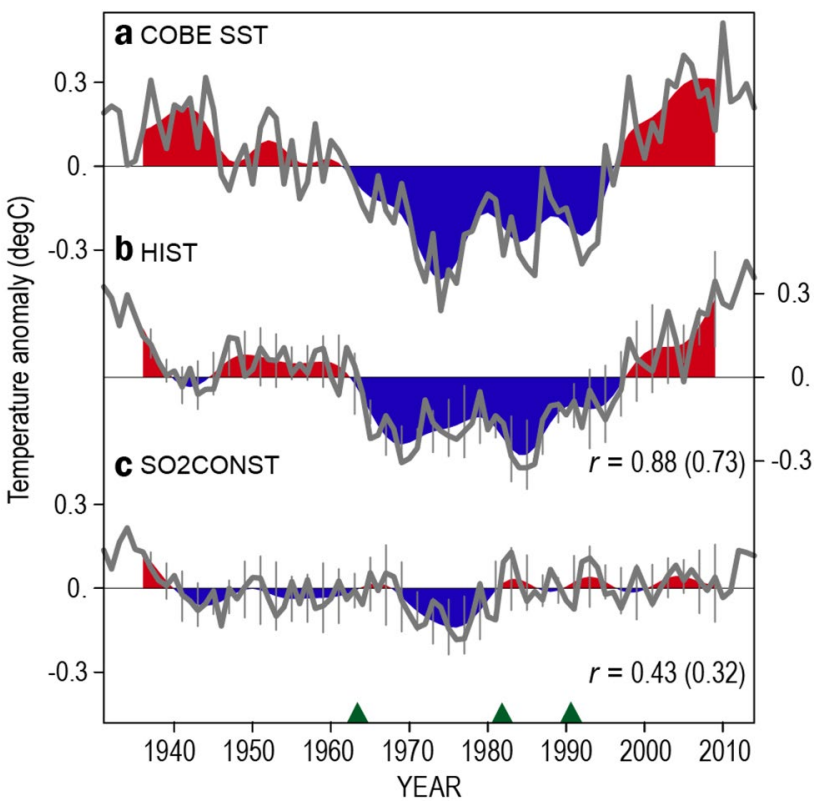

Fig. 2 Time series of the AMV index (gray curves) and its lowfrequency component (red and blue shading) for 1931-2014. (a) Observations, and $(b, c)$ ensemble means of the MIROC5.2 HIST and SO2CONST experiments, respectively. The thin bars in $(b, c)$ indicate the ensemble spread. Correlation coefficients between the simulated and observed low-frequency AMV indices are also shown (values using annual mean anomalies are in parentheses). Green triangles indicate three major volcanic eruptions (Agung, El Chichón, and Pinatubo)

the cooling, but SO2CONST, which excluded the timevarying sulphate aerosol emissions, failed to reproduce the observations (solid curves). The difference between the two ensembles is clearer when a 10-year low-pass filter was applied (shaded curves). Indeed, the correlation coefficient with the observed time series is 0.73 for the annual mean and 0.88 for the low-frequency anomalies in HIST (statistically significant at the $99 \%$ level), whereas SO2CONST shows a correlation of less than half. 

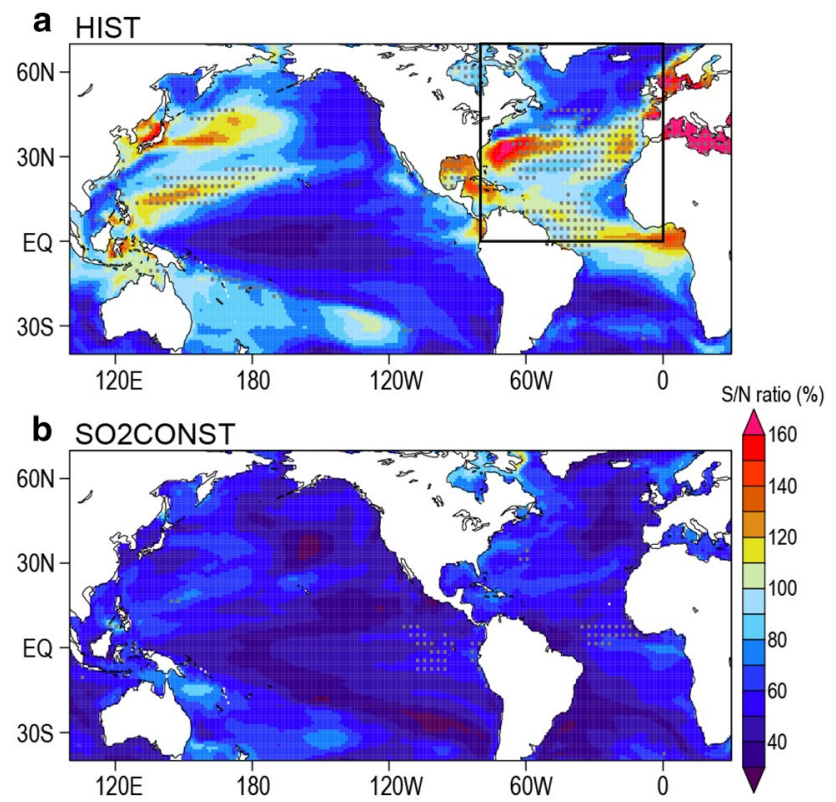

Fig. 3 S/N ratio of the decadal SST variability for 1931-2014 in a HIST and b SO2CONST. Stippling indicates regions exceeding 99\% significance for the correlation between observations and the ensemble mean anomalies. Box in a indicates the region used for the AMV index

Natural $\mathrm{SO}_{2}$ emissions due to three major volcanic eruptions were concurrent with the increase in anthropogenic $\mathrm{SO}_{2}$ emissions over North America and Europe, both of which would have acted to force the cold phase of the AMV (Fig. 1). As the sulphate aerosol radiative effect is negative, its contribution to warm periods for 1931-1960 and 1996-2014 is linked to reduced aerosol emissions (less cooling effects) relative to the 1960-1980s. However, VOLSO2CONST, which excluded only the time-varying natural sulphate aerosol emissions, was much better in reproducing the AMV index than SO2CONST (not shown). This indicates that the reproducibility of the observed AMV time series is lost in SO2CONST mainly due to prescribed anthropogenic sulphate aerosol forcing.

Observed detrended AMV indices for the warm and cold phases, defined by the averages for 1931-1960, 1961-1995, and 1996-2014 show anomalies of $0.1,-0.21$, and $0.22{ }^{\circ} \mathrm{C}$ with respect to the 1931-1990 mean (Table 3). These anomalies are reproduced by HIST, albeit with slightly underestimated magnitudes. With regard to multidecadal anomalies in HIST, anthropogenic sulphate aerosol shows the largest contributions of 63,53 , and $46 \%$ for the respective periods. The effect of volcanic aerosols is smaller, but significant compared to other aerosols and greenhouse gasses. The combined contribution by all sulphate aerosols is $83-87 \%$, which is slightly larger than the value of $76 \%$ obtained in the previous study (Booth et al. 2012). Given that the GHG-induced changes are monotonic and less on decadal time scales, it
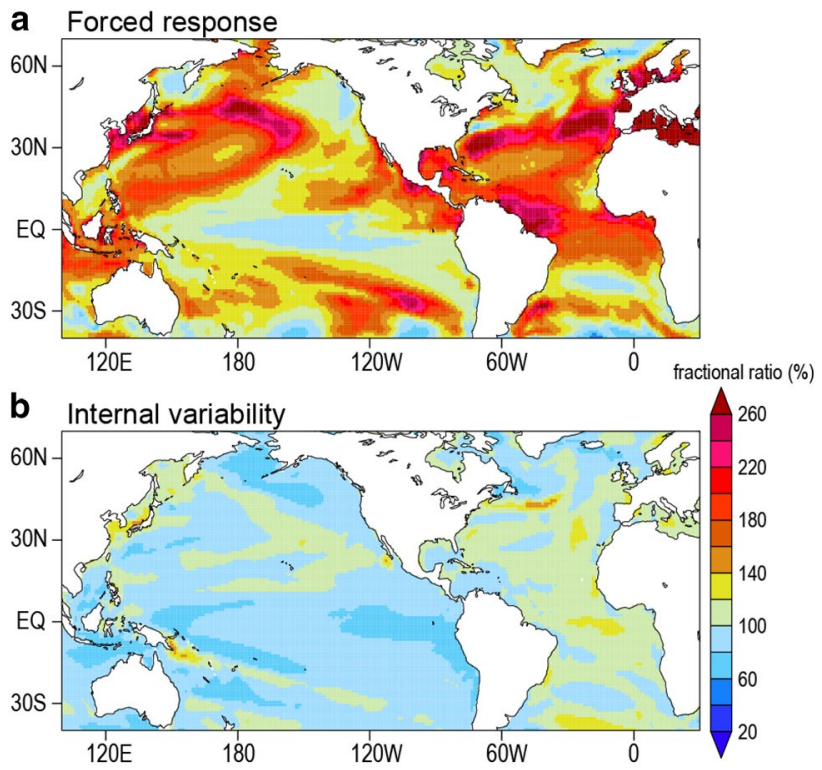

Fig. 4 Fractional ratio of the decadal SST variance for 1931-2014 between HIST and SO2CONST (former divided by the latter), based on $\mathbf{a}$ ensemble mean anomalies and $\mathbf{b}$ deviations from the ensemble mean, representing the forced and internally generated components, respectively

is not surprising that the anomalies in SO2CONST are not significant for any periods (Table 3 ).

Using the ensembles, we were able to decompose multidecadal variability into externally forced response and intrinsic fluctuations internal to the climate system. The total external component is modelled in the ensemble mean response to all the radiative forcings in HIST, while the externally forced historical response not linked to sulphate aerosols is represented by SO2CONST. By comparing the fraction of the low-frequency SST variance of the external components to the internal fluctuation in each ensemble, simply called the signal-to-noise $(\mathrm{S} / \mathrm{N})$ ratio, the extent to which $\mathrm{SO}_{2}$ emissions amplify the multidecadal variability is identified. The $\mathrm{S} / \mathrm{N}$ ratio in HIST is above unity in the tropical Atlantic, Gulf of Mexico, off the US East Coast, North Sea, and the Mediterranean Sea (Fig. 3a). This increased decadal variance, as well as a higher coherence with observations, is remarkable compared to the small and uniform $\mathrm{S} / \mathrm{N}$ ratio in SO2CONST (Fig. 3b).

Standard deviations (SDs) of decadal SST anomalies using the ensemble mean and deviations from the ensemble mean represent the magnitude of external and internal variability, respectively. These fields obtained from HIST and SO2CONST can be combined in a manner different from Fig. 3. Namely, the fraction of SD for the ensemble-mean anomalies between HIST and SO2CONST reveals the effect of sulphate aerosols in changing the amplitude of externally 
Fig. 5 Low-frequency anomalies in a, $\mathbf{d}$ surface clear-sky shortwave radiation, $\mathbf{b}$, e surface shortwave cloud-radiative effect, and $\mathbf{c}, \mathbf{f}$ cloud cover regressed on the low-frequency AMV index in HIST. a, b, c Represent the forced component while $\mathbf{d}, \mathbf{e}, \mathbf{f}$ are the internally generated components of the ensemble. The regression is based on detrended and lowpass filtered anomalies. Dots indicate regions exceeding $95 \%$ significance
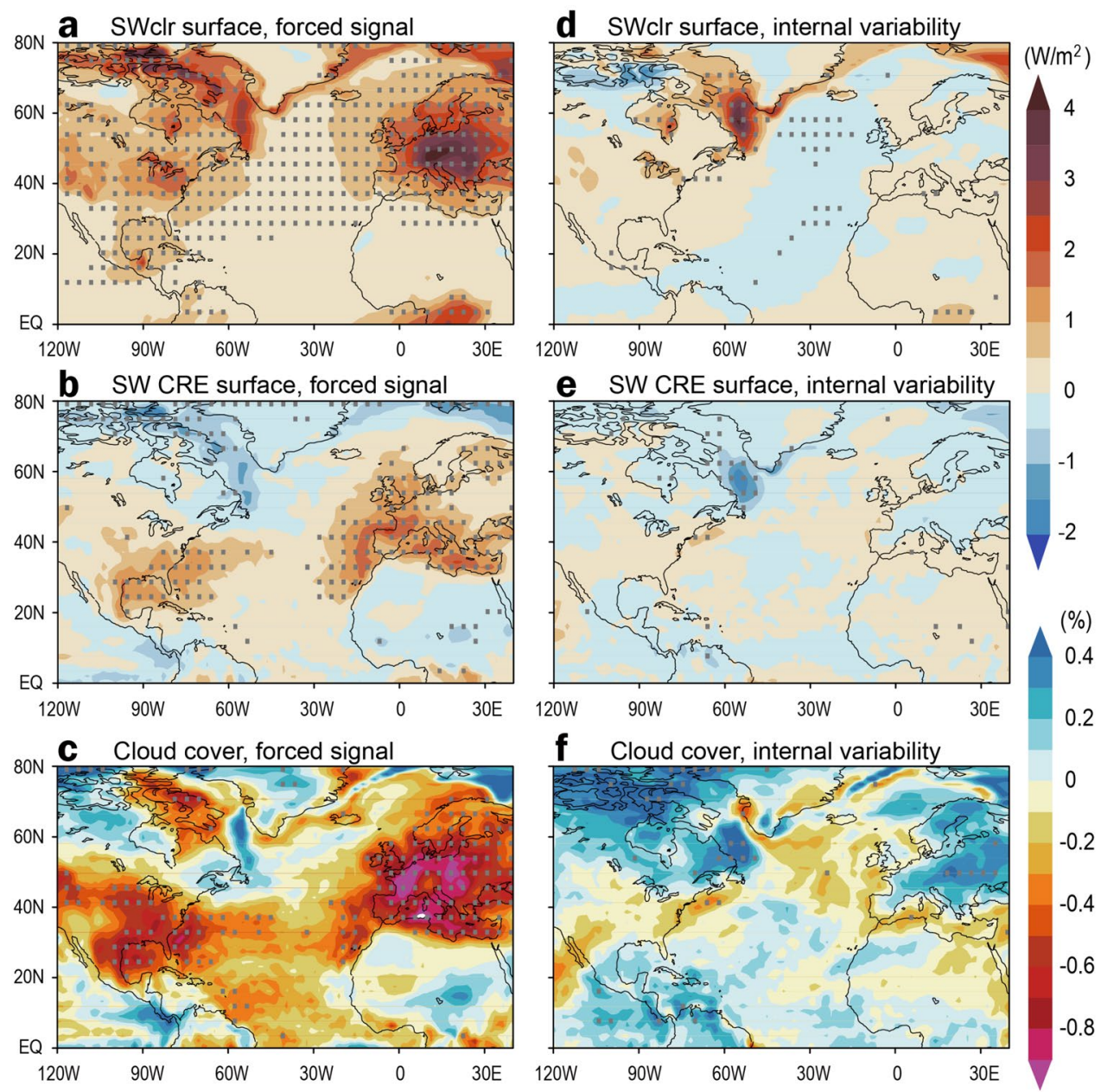

forced decadal fluctuations. Likewise, the fraction of SD for the intra-ensemble anomalies exhibits whether $\mathrm{SO}_{2}$ emissions modulate the amplitude of internal variability. Maps of these fractional ratios indicate a clear amplification of the external component in the extratropical Pacific and Atlantic in HIST while the amplitude of the internal variability for the two ensembles is different by at most $\pm 20 \%$ between the ensembles (Fig. 4). The aerosol-driven enhancement of the $\mathrm{S} / \mathrm{N}$ ratio is also seen in the western North Pacific, where sulphate aerosol forcing is shown to have contributed to the decadal SST variability (Takahashi and Watanabe 2016). Since the S/N ratio is small in the tropical Pacific in both ensembles, the north-south contrast in amplitude of externally forced SST variance in the North Atlantic would have reflected the spatial structure of aerosol radiative forcing, but not a different efficacy of ocean mixing (Terray 2012).

Sulphate aerosol forcing of climate includes direct and indirect radiative effects (Lohmann and Feichter 2005). Sources of anthropogenic sulphate aerosols are highly concentrated over Northern Hemisphere landmasses, but the climate response emerges not only locally but also on a larger scale due to atmosphere-ocean interactions the presence of clouds both cause a remote response to the aerosol forcing to occur (Xie et al. 2013; Carslaw et al. 2013). Sulphate aerosol radiative forcing as measured by surface shortwave radiation shows that large forcing occurs over the US, Europe, and adjacent coastal regions (Fig. 5a-c). Compared to the direct effect, the indirect effect associated with a reduction in cloud cover tends to dominate at slightly lower latitudes (Fig. 5b, c), but both work to uniformly increase the North Atlantic SST. Surface shortwave radiation anomalies associated with the internal variability do not show a systematic pattern (Fig. 5d-f), except for a compensating anomaly between the clear-sky and cloud radiative effects in the Labrador Sea (perhaps linked to an anomalous sea ice conditions).

The importance of aerosols as the primary driver of the AMV has been questioned because of a discrepancy in ocean interior temperature changes between model and observation (Zhang et al. 2013). In order to strengthen the credibility of our simulations, we examined the global mean SAT and the 0-700 m ocean heat content $\left(\mathrm{HC}_{700}\right)$ 

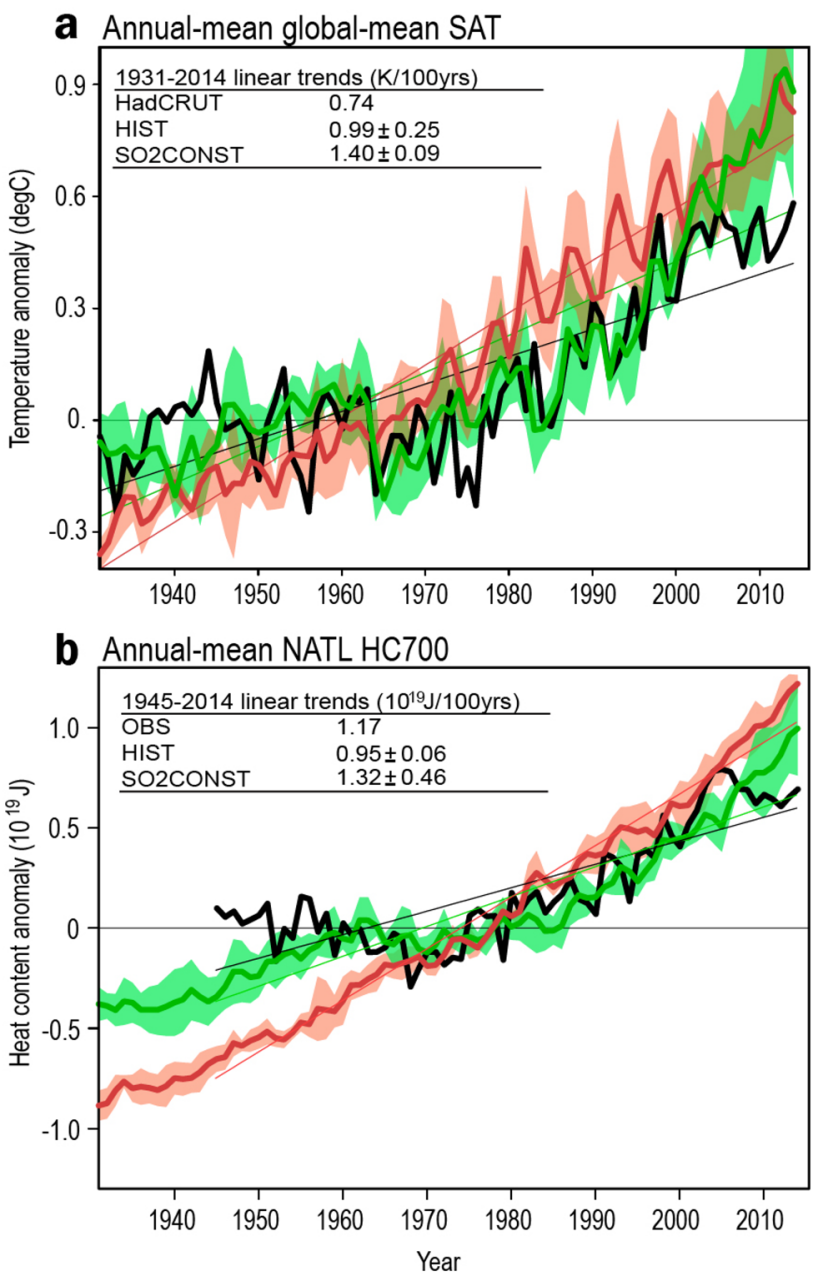

Fig. 6 a Global mean surface air temperature and $\mathbf{b}$ the North Atlantic $\mathrm{HC}_{700}$ anomalies for 1931-2014, derived from observations (black), ensemble means of HIST (green) and SO2CONST (red). Shading indicates the ensemble spread. Observed $\mathrm{HC}_{700}$ are available after 1945. Linear trends for 1931-2014 in a and 1945-2014 for b are shown by thin lines (values presented at the top). The panel a was reprinted from Fig. S8 of Takahashi and Watanabe (2016)

in the North Atlantic (Fig. 6). As expected, the warming trend of global SAT in SO2CONST is 1.4 times larger than that of HIST, the latter being consistent with observation. A greater reproducibility of $\mathrm{HC}_{700}$ is seen in HIST as well, showing an increasing trend similar to the observations for 1945-2014. The long-term trend is overrepresented in SO2CONST, which furthermore lacks multidecadal variations. Therefore, the failure to capture the observed heat content change in the previous model study (Booth et al. 2012), linking aerosols to the AMV, is not observed in the MIROC5.2 simulations.

\subsection{Forced and internally generated variability in the atmosphere}

Impact of the AMV on atmospheric circulation and land hydrology is well represented in HIST. The regression of detrended low-frequency anomalies in SST, sea level pressure (SLP) and land precipitation on the AMV index using the whole ensemble, shows a meridional dipole pattern of SLP and moistening over the Amazon, Sahel, and Central Europe, associated with uniformly positive SST anomalies displaying a maximum to the south of Greenland (Fig. 7a, b). Except for a lack of drying over the southeastern US and the Mediterranean region, the simulated decadal anomalies resemble the observations.

An influence of the AMV on Sahel rainfall, caused by the SST contrast between the North and South Atlantic, is well established (Folland et al. 1986; Chang et al. 2011). Also, warming of the tropical North Atlantic during a positive AMV works to increase rainfall over Europe (Sutton and Hodson 2005). Here we show that these impacts are associated with aerosol-driven AMV changes and unlikely to have arose from internally generated ocean variability alone, based on comparison of simulations (Fig. 7c, d) with the observed changes (Fig. 7a).

While the AMV pattern does not have a large seasonality in terms of the SST anomalies, associated precipitation anomalies do show a contrast between June-August (JJA) and December-February (DJF) seasons. This is clearly seen in the regression maps similar to Fig. 7, using the seasonal mean anomalies (Fig. 8). Increasing precipitation over Europe and Sahel during the positive AMV is remarkable in the boreal summer season in both observations and HIST, consistent with the previous studies (Folland et al. 1986; Sutton and Hodson 2005; Zhang and Delworth 2006; Knight et al. 2006). Impact of the aerosol-forced SST variations on land precipitation (Fig. 7c) is thus the signature of summer. When the precipitation anomaly in HIST is decomposed into the forced and internal components, the summertime signals are observed only in the former, consistent with Fig. 7c, d.

Positive aerosol forcing during the positive phase of the AMV would have warmed land surfaces locally, which should lead to drier condition on land in contrast to the observed increased rainfall over Europe and the Sahel (Fig. 7c). The main reason why the land surface becomes wetter with warmer temperatures is the increase in tropical water vapour as seen in the precipitable water anomalies regressed on the external component of the AMV (Fig. 9a). This increase in tropical water vapour arises from larger SST anomalies in the tropical Atlantic and the tropical western Pacific (Fig. 4a), which stimulate evaporation at the ocean surface. Because the tropical atmosphere cannot maintain a strong zonal gradient (Sobel et al. 2001), these wetter anomalies expand to 

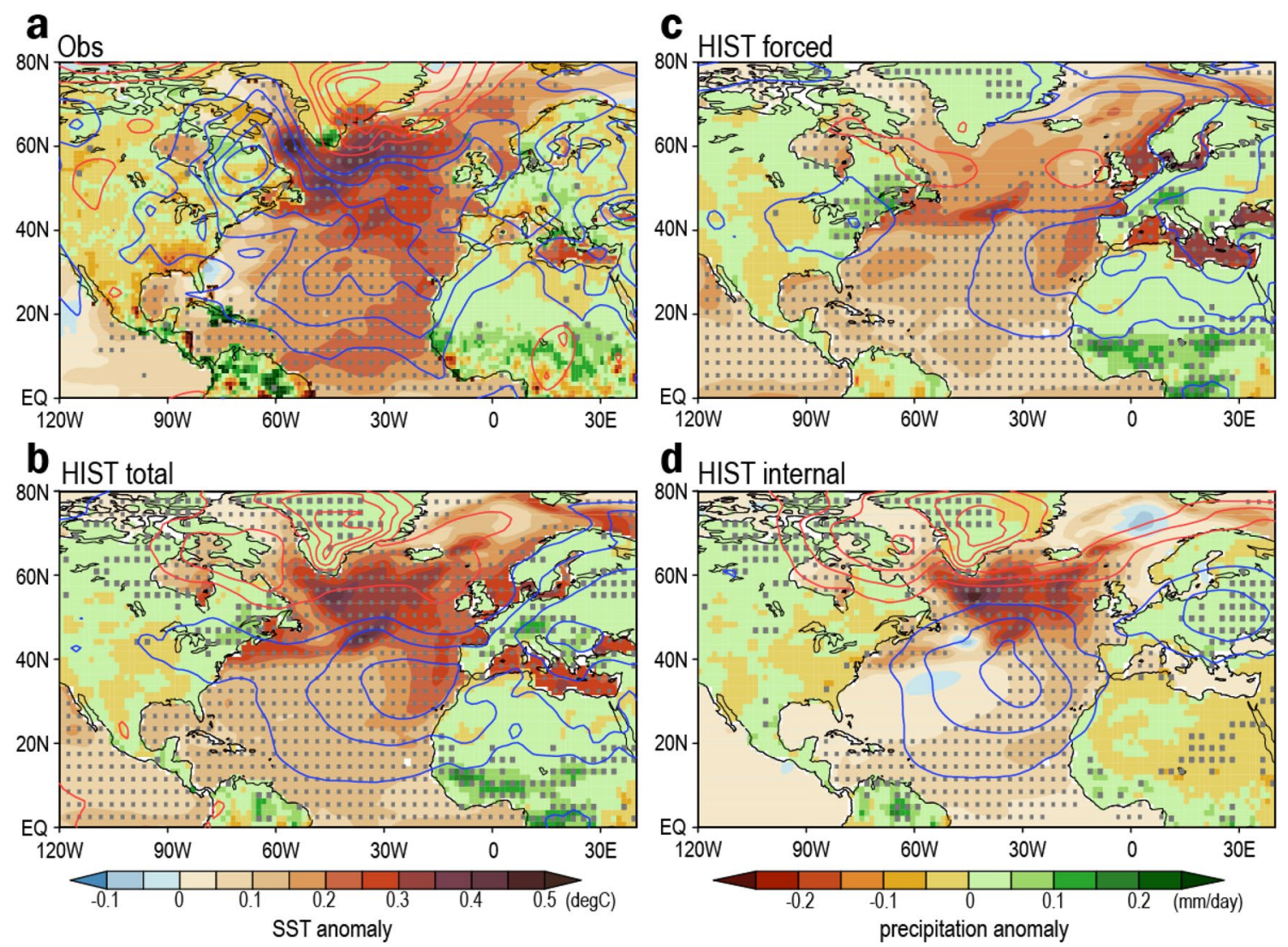

Fig. 7 Low-frequency anomalies in SST (shading over the ocean), SLP (contour, $0.05 \mathrm{hPa}$ interval), and land precipitation (shading over land) regressed on the low-frequency AMV index. a Observations, bd MIROC5.2 HIST. The regression using the combined five members (b) represents the total anomalies, which are decomposed into exter-

tropical land areas. In addition, anomalous transport of vertically integrated water vapour, a part of the circulation response to the aerosol forcing, works to bring more moisture to Europe and the Sahel (Fig. 9a). Surface circulation anomalies associated with the internal decadal variability are confined to regions over the ocean (Fig. 7d), contributing less to a landward anomalous water vapour transport (Fig. 9b).

The SLP anomalies associated with internal variability are akin to the North Atlantic Oscillation (NAO) and coexist with a less widespread SST anomaly pattern focused around the subpolar gyre (contours in Fig. 7d). Consistent with Fig. 3a, the external component alone cannot explain much of the observed SST anomaly in that region, where observed SST and sea surface salinity (SSS) fluctuate in phase on both decadal and multidecadal time scales (Fig. 10a). In this region, internally generated SSS variability is more coherent with the AMV (Fig. 10c, d), which suggests that the deep water formation and large-scale ocean circulation is less linked to the sulphate aerosol forcing (Curry et al. 1998).

nally driven (c) and internally generated (d) anomalies obtained from the regression using the ensemble mean and intra-ensemble fields. Stippling indicates regions exceeding 95\% significance for SST and precipitation anomalies

\subsection{Internal and external components in AMOC}

The intrinsic timescale of the forced and internally generated components of the AMV was identified with the autocorrelation function of the ensemble mean and ensemble deviations of the AMV index (Fig. 11a, thin curves). Both observation and ensemble mean show a long duration of one phase of about 30 years, whereas the internal variability has a shorter duration of 10-15 years with an oscillatory nature. Given these different timescales of variability, it is convenient to refer to 'Atlantic Multidecadal Oscillation (AMO)' as the internal component of the AMV (Delworth et al. 1993; Delworth and Mann 2000; Ting et al. 2009; Zhang and Wang 2013; Steinman et al. 2015).

The externally forced variability is significantly correlated with the AMOC index, defined by the maximum value of the meridional streamfunction at $40^{\circ} \mathrm{N}$, when the AMV leads AMOC by 5 years (Fig. $11 \mathrm{a}$, thick red curve). This indicates a delayed response of the AMOC to the SST change, and is consistent with a strengthened AMOC after the cooling period of the AMV as revealed 


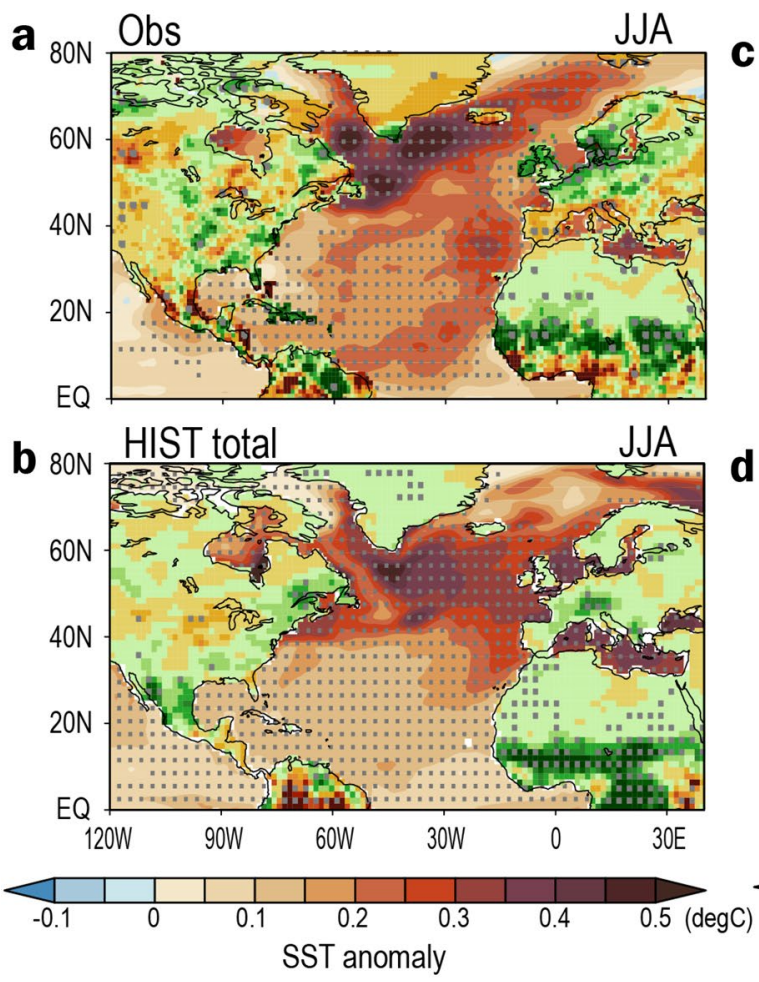

Fig. 8 Low-frequency anomalies in SST (shading over the ocean) and land precipitation (shading over land) regressed on the low-frequency AMV index. a, c Observations and b, d MIROC5.2 HIST. The anom-

in CGCMs (Delworth and Dixon 2006; Cheng et al. 2013; Menary and Scaife 2014; Undorf et al. 2018). Unlike the externally driven component, the AMO has a greater correlation with the associated internal variability of AMOC, showing a positive correlation from -9 to +1 years and a negative correlation from +3 to +14 years (Fig. 11a, thick blue curve). This lagged relationship between AMO and AMOC is reminiscent of the oscillator (Delworth et al. 1993; Delworth and Mann 2000), and the positive simultaneous correlation between the AMO and AMOC indices is a common property of the internal oscillation in CGCMs (Tandon and Kushner 2015). Indeed, the AMOC index contains an external forced variability which is weaker than the internal fluctuations unlike the AMV index (Fig. 11b, c).

Maps of the decadal anomalies in SST, SLP, $\mathrm{HC}_{700}$, and AMOC of internal variability associated with the AMO in HIST are displayed in Fig. 12. The simultaneously regressed anomalies of SST and SLP are identical to Fig. 7d. The features shown were very similar in the other ensembles of SO2CONST and VOLSO2CONST. With a lag between -10 and -5 years, subpolar SST decreases in association with the positive NAO-like circulation anomaly. The cold subpolar region intensifies mixing and thus accelerates AMOC, which eventually changes the sign of subpolar SST

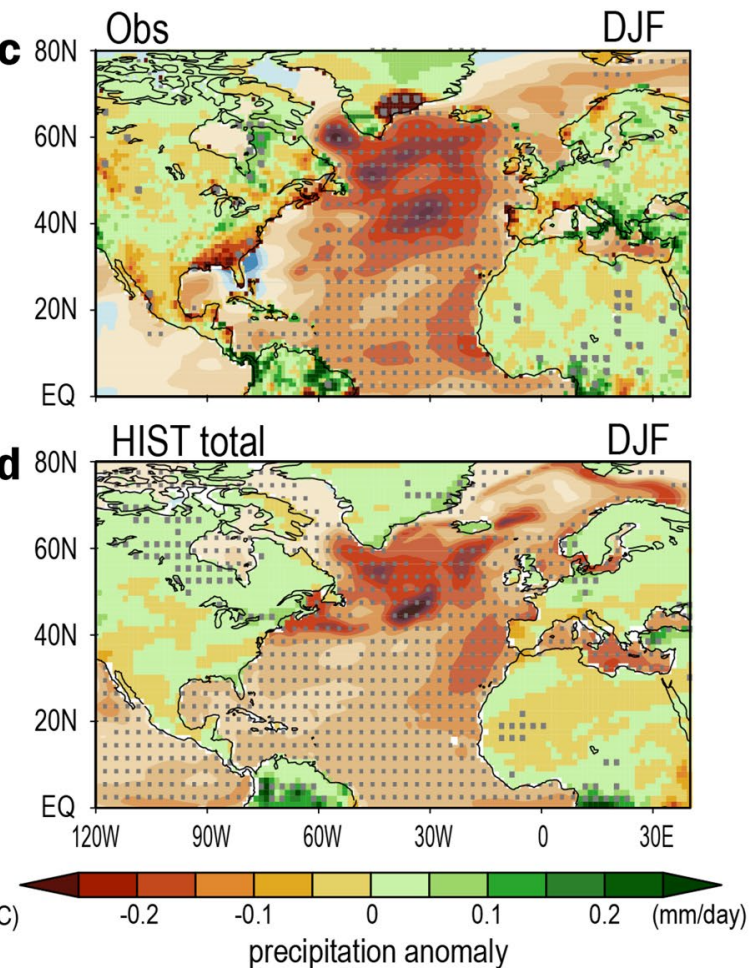

aly fields are constructed based on JJA and DJF averages in $\mathbf{a}, \mathbf{b}$ and c, d, respectively. Convention follows Fig. 7

via enhanced northward heat transport. Once the subpolar region warms, it in turn works to decelerate the AMOC by suppressing vertical mixing. This mechanism is similar to an advective oscillator, which is clearer in the internal variability than in the total variability (Saravanan and McWilliams 1998; Zhang and Wang 2013; Tandon and Kushner 2015). The AMOC weakens after the peak of the AMO probably excited by the NAO, but there was no clear indication that the atmosphere responds to this weakening in order to change the AMO phase. The delayed oceanic response to the NAO is reminiscent of observed anomalies identified in the mid-1990s (Robson et al. 2012).

A careful comparison of the simultaneous regression maps between SST and $\mathrm{HC}_{700}$ in Fig. 12 reveals an opposite sign of anomalies in the North Tropical Atlantic region. This anti-correlation between the surface and subsurface temperature variations has been denoted as a feature of the AMO (Zhang 2007). The lack of this anti-correlation was one of the caveats of the simulation demonstrating the aerosol driving of the AMV (Zhang et al. 2013), but we found in the HIST total anomalies that the spatial patterns of both SST and subsurface ocean temperature were represented reasonably well by MIROC5.2. 


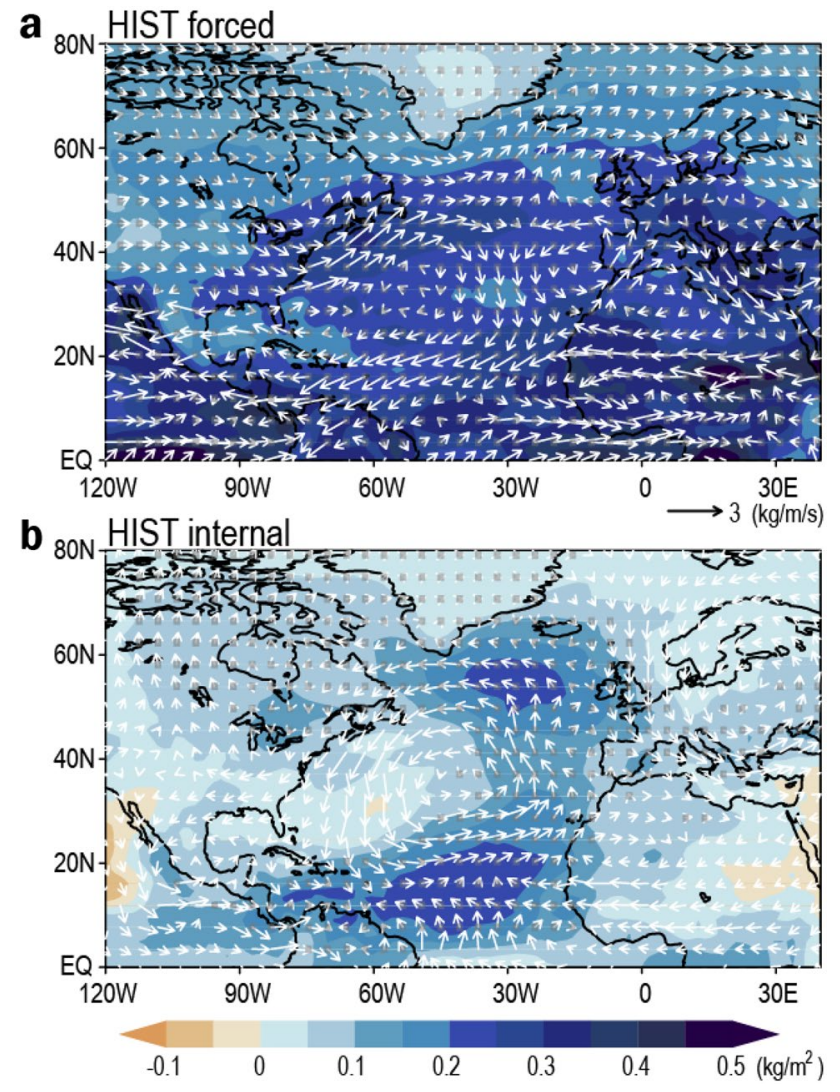

Fig. 9 Low-frequency anomalies in precipitable water (shaded) and vertically integrated water vapour fluxes (arrows) regressed on the low-frequency AMV index in HIST. a External and b internal components of the ensemble. Dots indicate regions exceeding 95\% significance of the precipitable water anomalies

\section{Implication for future projections}

In the Representative Concentration Pathways (RCP) scenarios for the CMIP5 future climate simulations, anthropogenic $\mathrm{SO}_{2}$ emissions are assumed to decline besides no further volcanic eruption will occur (van Vuuren et al. 2011). Therefore, we expect that the externally forced multidecadal variability will be reduced toward the end of this century under these scenarios (cf. Fig. 3b). This possibility was examined using CMIP5 models having five-member initial condition ensembles for both historical and RCP4.5 simulations.

The multi-model ensemble for 2031-2100 indeed shows a smaller S/N ratio in decadal SST variance compared to the 1931-2000 period (Fig. 13). As in MIROC5.2, forced decadal SST anomalies for 1931-2000 have been amplified in the Atlantic and the tropical western Pacific, suggesting a primary role of sulphate aerosol effects. The pattern of the $\mathrm{S} / \mathrm{N}$ ratio is model dependent, but an amplification in the tropical North Atlantic and the Mediterranean Sea during the twentieth century was commonly found (Fig. 14). We therefore conclude that future North Atlantic multidecadal
SST variability will be increasingly generated by internal processes if no large volcanic eruption occurs as is assumed in the RCP forcing scenario. Considering the difference in structure between internal variability and forced response (Fig. 7c, d), SST anomalies in the future AMV will dominate in higher latitudes and have lesser impact on boreal summer precipitation over surrounding land areas. This condition may change under other scenarios where air quality measures are not aggressively adopted or large eruptions occur.

The S/N ratio of the decadal SST anomalies, shown in Fig. 13, was calculated for each model (Fig. 14). The pattern of amplification for 1931-2000 varies across models, but the reduction of the $\mathrm{S} / \mathrm{N}$ ratio in future climate is a common and thus robust feature of the CMIP5 simulation. A large $\mathrm{S} / \mathrm{N}$ ratio of decadal SST anomalies in the tropical Atlantic and the tropical western Pacific for 1931-2000 is seen in all models (and also in HIST but not VOLSO2CONST), suggesting a vital role of the direct radiative effect due to volcanic sulphate aerosols. Amplification of the forced variability in the Mediterranean Sea and along the Gulf Stream is identified only in CanESM2, CSIRO-Mk3.6.0, and MIROC5, all of which have incorporated the aerosol indirect effect (Table 2). This is consistent with the decadal anomalies in surface cloud radiative effect and cloud cover (Booth et al. 2012; see also Fig. 5b, c).

\section{Concluding discussion}

In this study, we attempted to quantify the influence of sulphate aerosol radiative forcing to the AMV over the past eight decades, using ensembles of the MIROC5.2 attribution experiments. Using single model experiments, we conclude that the sulphate aerosol forcing is crucial for reproducing the variance and phase changes of the observed decadal SST anomalies associated with the AMV. Specifically, past changes in anthropogenic sulphate emissions explain more than half of the externally forced decadal SST variations, which significantly increased precipitation over Europe and the Sahel during the positive phase of the AMV. The above conclusions overall support Booth et al. (2012) and other recent studies showing the dominant role of the external forcing in the observed AMV cycles (Murphy et al. 2017; Bellomo et al. 2018; Undorf et al. 2018). Yet, it is clear from Fig. 7 that the internally generated SST variability (called the AMO in this study) in the Atlantic atmosphere-ocean system is an important element of the observed AMV, in the subpolar region in particular.

It has been reported that the dominant frequency of the AMO varies among GCMs albeit the large decadal and multidecadal variance is commonly found (Zhang and Wang 2013). There is a model showing a long timescale of 5-6 decades in the AMOC variability (Vellinga and $\mathrm{Wu}$ 
a

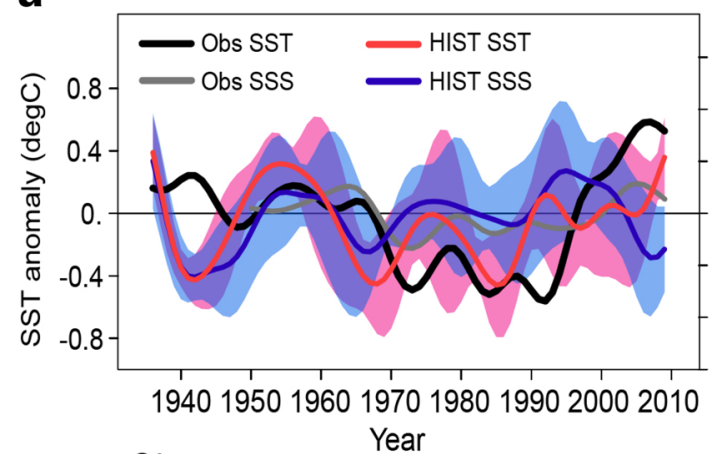

b

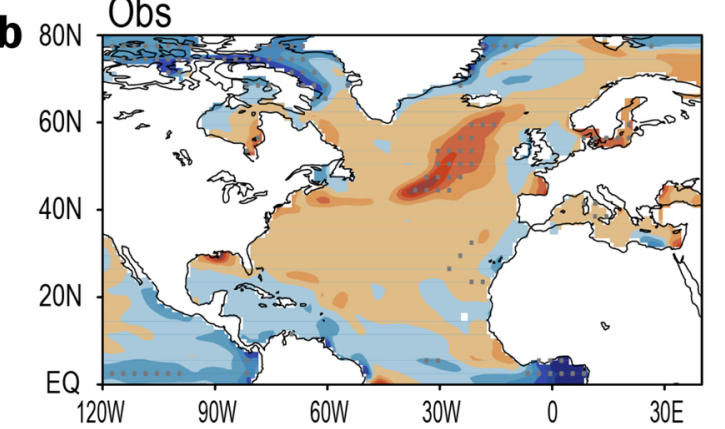

C ${ }_{80 \mathrm{~N}}$ HIST forced

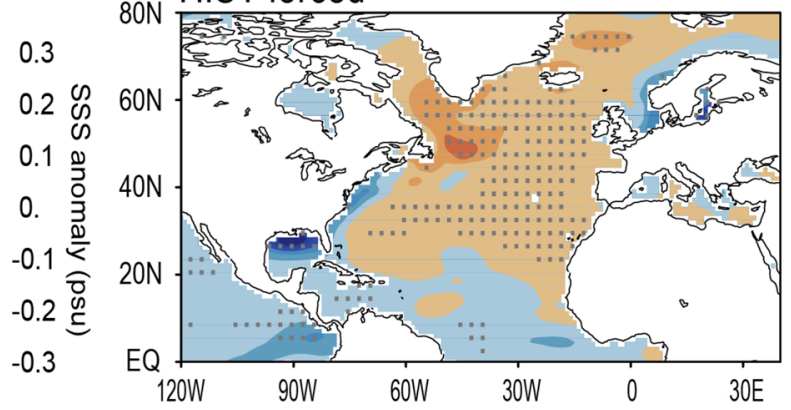

d $80 \mathrm{~N}$ HIST internal

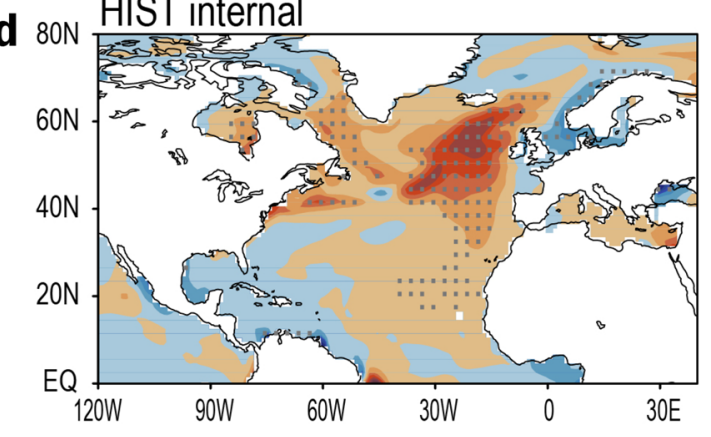

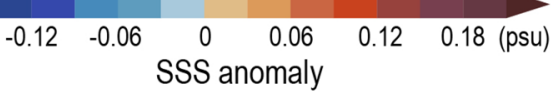

Fig. 10 a Time series of the North Atlantic subpolar SST and SSS anomalies $\left(60 \mathrm{~W}^{\circ}-0^{\circ}, 50^{\circ}-65^{\circ} \mathrm{N}\right)$ and $\mathbf{b}-\mathbf{d}$ low-frequency anomalies in SSS regressed on the low-frequency AMV index in observations, external and internal components of HIST, respectively

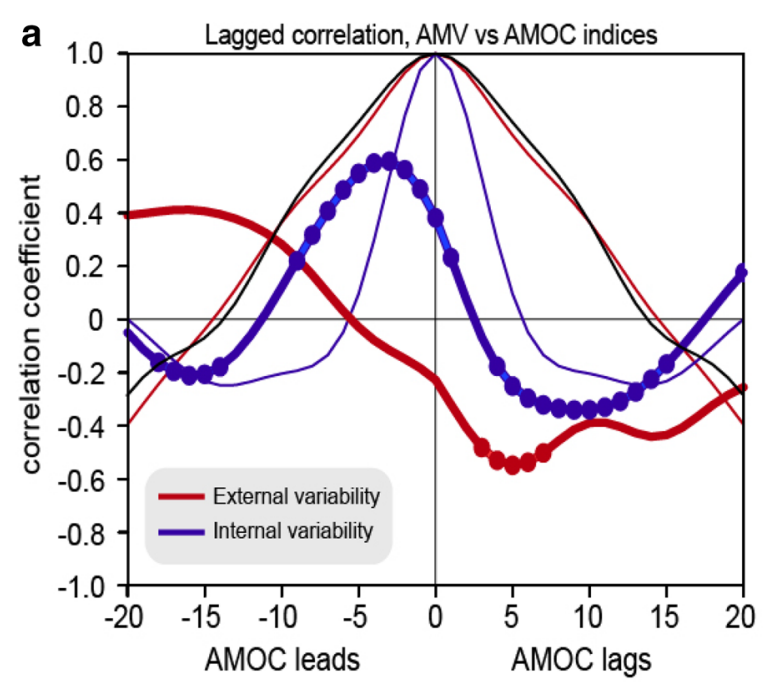

Lag (year)
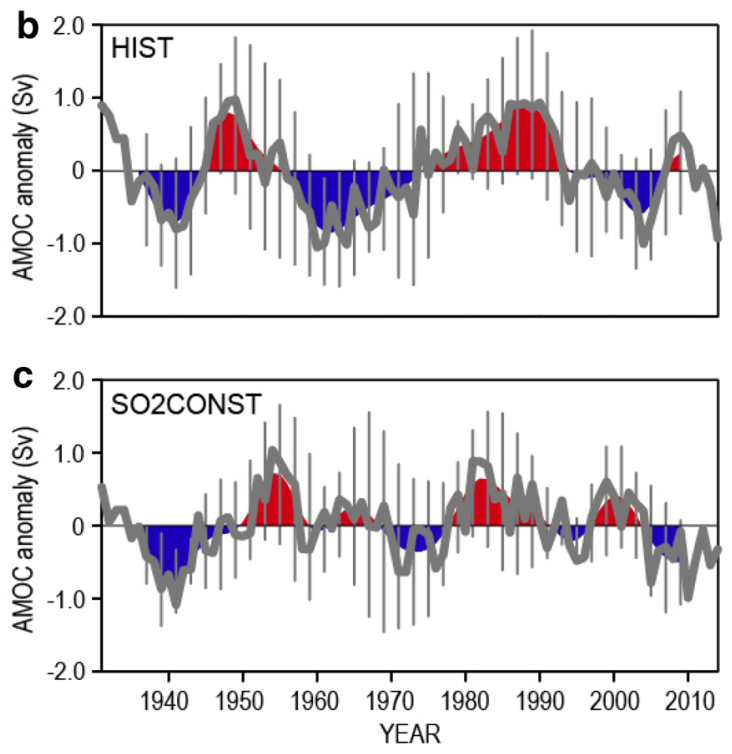

relation coefficient statistically significant at the $95 \%$ level is marked by dots. Autocorrelation of the observed AMV index is shown by the black curve. $\mathbf{b}$, $\mathbf{c}$ Time series of the AMOC index in HIST and SO2CONST. Convention follows Fig. 2
Fig. 11 a Lagged correlation between the AMV and AMOC indices (thick curves) and the autocorrelation of the AMV index (thin curves) in HIST, using the ensemble-mean anomalies (red) and deviations from the ensemble mean (blue) for 1931-2014, representing forced and internally generated components, respectively. The cor- 

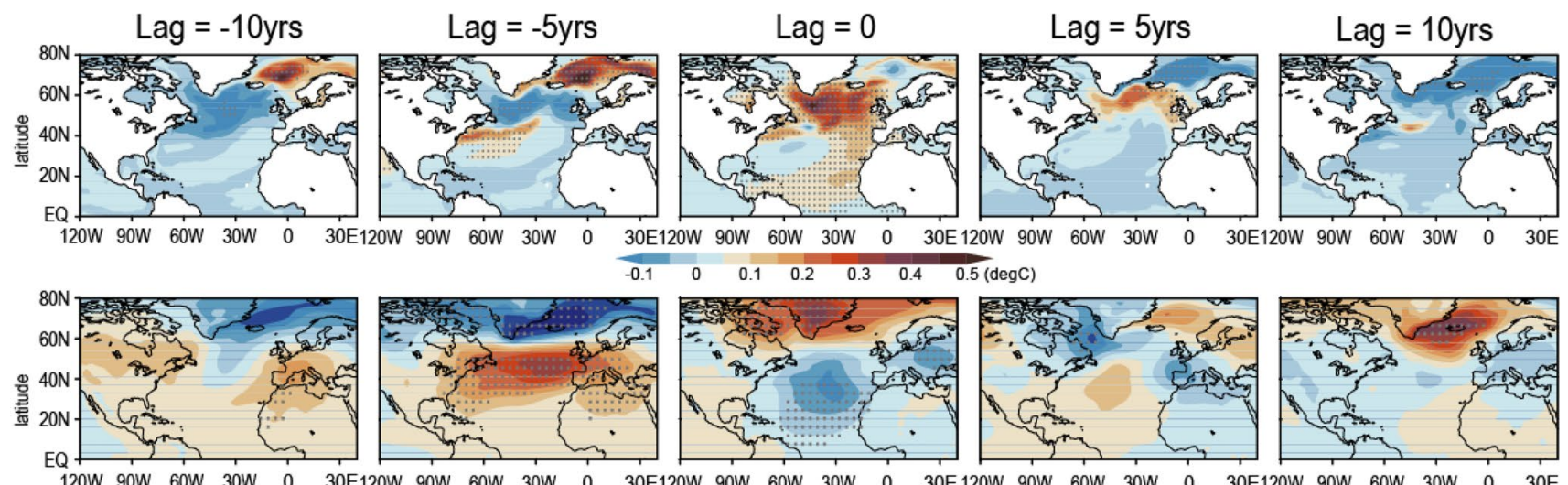
$\begin{array}{ccccccc}-0.3 & -0.2 & -0.1 & 0 & 0.1 & 0.2 & 0.3(\mathrm{hPa}) \\ \end{array}$
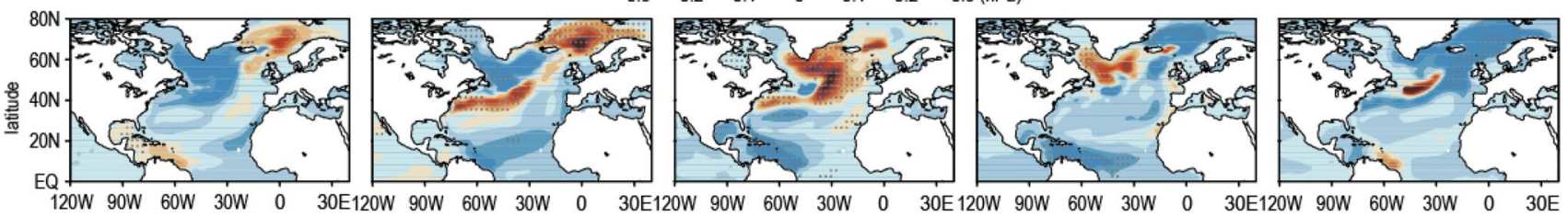
$\begin{array}{lllllll}-0.1 & 0 & 0.1 & 0.2 & 0.3 & 0.4 & 0.5\left(10^{19} \mathrm{~J}\right)\end{array}$
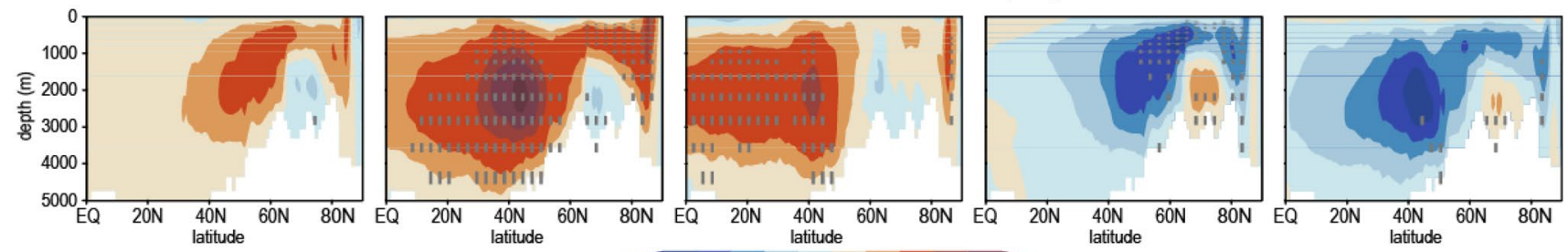

$\begin{array}{ccccccccccc}-0.5 & -0.4 & -0.3 & -0.2 & -0.1 & 0 & 0.1 & 0.2 & 0.3 & 0.4 & 0.5(\mathrm{Sw})\end{array}$

Fig. 12 Lagged regression maps for internal decadal fluctuations associated with the AMO in HIST. (From top to bottom) SST, SLP, $\mathrm{HC}_{700}$, and AMOC at lag times of (from left to right) $-10,-5,0,5$, and 10 years. The regression is based on detrended and low-pass fil-

2004) whereas others show a faster cycle of 20-30 years akin to MIROC5.2 (Griffies et al. 2011). It is likely that the frequency and amplitude of the internal SST variability around the subpolar gyre vary across GCMs, but it is not obvious the extent to which it impacts on the basin-wide forced SST variability, i.e., AMV. Also, the presence of externally forced component in AMOC variability is an intriguing feature, which may depend on characteristics of the AMOC in a control simulation. Unfortunately, the attribution experiments such as presented in this work are not available in CMIP5, so that a multi-model assessment is not possible at the present time. We expect that our results provide a benchmark for future multi-model studies using CMIP6 models in which comparisons can be made between experiments using a similar configuration to SO2CONST but with different GCMs.

Our results provide a useful guideline for decadal climate predictions over the Euro-Atlantic sector. Namely, initialised decadal experiments targeted to predict internally generated components of the AMV, which will dominate as sulphate aerosol effects are declining, will become more tered anomalies after ensemble mean was subtracted. Grey dots indicate the correlation coefficient significant at the $99 \%$ level. Negative lag implies anomalies leading to the AMO
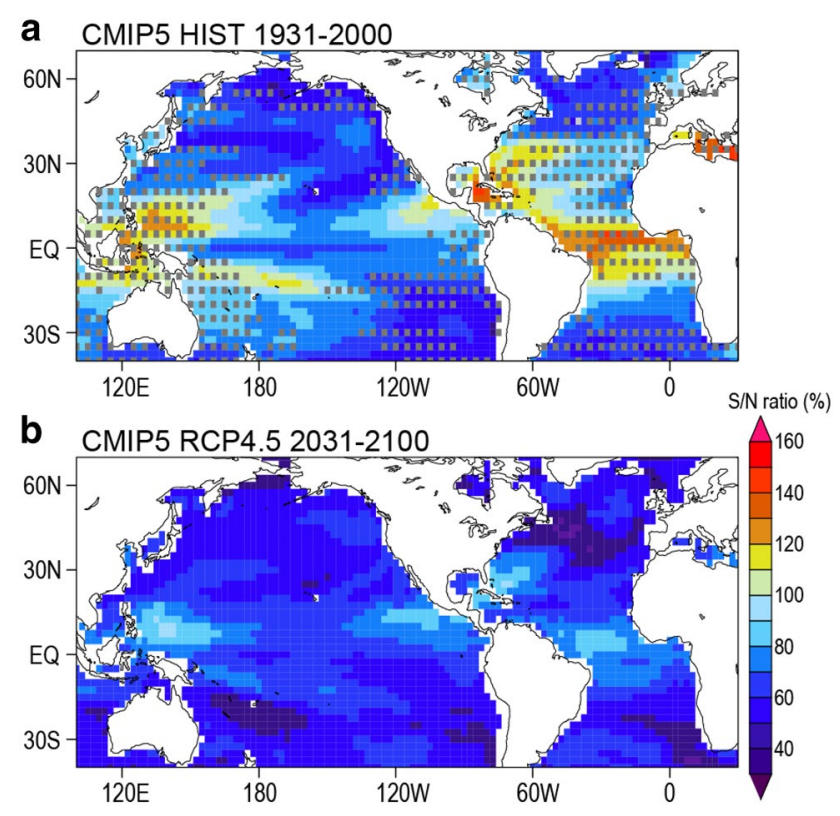

Fig. 13 S/N ratio of the decadal SST variability for a 1931-2000 and b 2031-2100 in CMIP5 multimodel ensembles of the historical and RCP4.5 experiments 

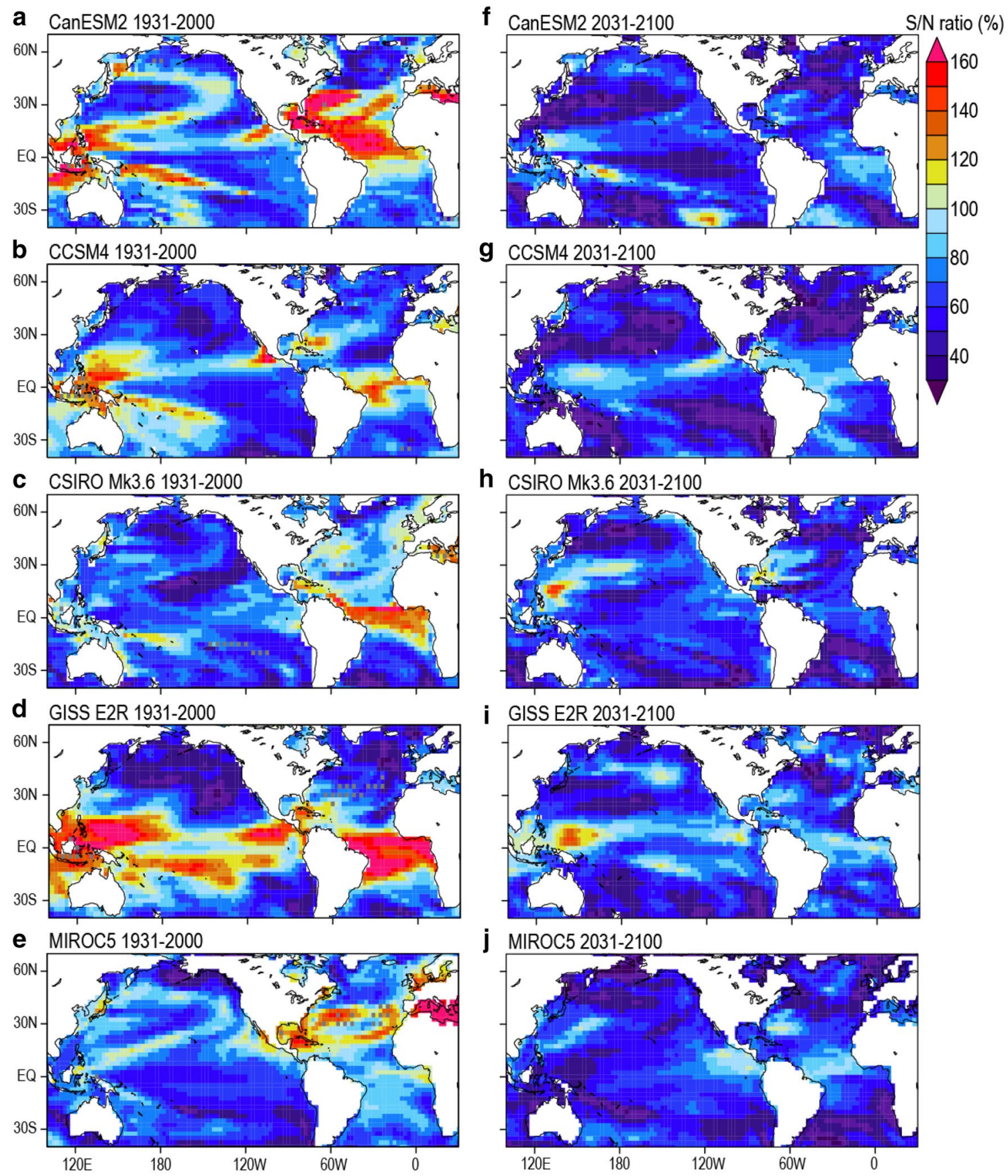

Fig. 14 S/N ratio of the decadal SST variability for $\mathbf{a}-\mathbf{e}$ 1931-2000 and $\mathbf{f}-\mathbf{j}$ 2031-2100 in individual CMIP5 models. Convention follows Fig. 12

important for predicting future changes. However, care must be taken when assessing the predictive skill of initialised ensembles using a retrospective prediction for past decades, as externally forced responses appear to have exerted a considerable influence over the observed AMV. The present positive AMV may enter a negative phase if a large volcanic eruption occurs (Shiogama et al. 2010) or the AMOC is continuously weakened (Robson et al. 2014). With these competing contributions, such a turnabout of the AMV will be challenging to predict.

Acknowledgements We acknowledge the modelling groups, the PCMDI and the WCRP's WGCM for their efforts in making the CMIP5 multi-model data set available. We thank $\mathrm{M}$. Ishii for providing subsurface ocean temperature data set and B. Booth for continuous encouragement. This work was supported by the Integrated Research Program for Advancing Climate Models (TOUGOU program) from the Ministry of Education, Culture, Sports, Science and Technology (MEXT), Japan. 
Open Access This article is distributed under the terms of the Creative Commons Attribution 4.0 International License (http://creativeco mmons.org/licenses/by/4.0/), which permits unrestricted use, distribution, and reproduction in any medium, provided you give appropriate credit to the original author(s) and the source, provide a link to the Creative Commons license, and indicate if changes were made.

\section{References}

Allan RJ, Ansell TJ (2006) A new globally complete monthly historical mean sea level pressure data set (HadSLP2): 1850-2004. J Clim 19:5816-5842

Bellomo K, Murphy L, Cane MA, Clement AC (2018) Historical forcings as main drivers of the Atlantic multidecadal variability in the CESM large ensemble. Clim Dyn 50:3687-3698

Booth BBB, Dunstone NJ, Halloran PR, Andrews T, Bellouin N (2012) Aerosols implicated as a prime driver of twentieth-century North Atlantic climate variability. Nature 484:228-232

Carslaw KS et al (2013) Large contribution of natural aerosols to uncertainty in indirect forcing. Nature 503:67-71

Chang CY, Chiang JCH, Wehner MF, Friedman AR, Ruedy R (2011) Sulphate aerosol control of tropical Atlantic climate over the twentieth century. J Clim 24:2540-2555

Cheng W, Chiang JCH, Zhang D (2013) Atlantic meridional overturning circulation (AMOC) in CMIP5 models: RCP and historical simulations. J Clim 26:7187-7197

Clement A, Bellomo K, Murphy LN, Cane MA, Mauritsen T, Radel G, Stevens B (2015) The Atlantic multidecadal oscillation without a role for ocean circulation. Science 350:320-324. https:// doi.org/10.1126/science.aab3980

Curry RG, McCartney MS, Joyce TM (1998) Oceanic transport of subpolar climate signals to mid-depth subtropical waters. Nature 391:575-577

Delworth TL, Dixon KW (2006) Have anthropogenic aerosols delayed a greenhouse gas-induced weakening of the North Atlantic thermohaline circulation? Geophys Res Lett 33:L02606. https://doi.org/10.1029/2005GL024980

Delworth TL, Mann ME (2000) Observed and simulated multidecadal variability in the Northern Hemisphere. Clim Dyn 16:661-676

Delworth TL, Manabe S, Stouffer RJ (1993) Interdecadal variations of the thermohaline circulation in a coupled ocean-atmosphere model. J Clim 6:1993-2011

Dunstone NJ, Smith DM, Booth BBB, Hermanson L, Eade R (2013) Anthropogenic aerosol forcing of Atlantic tropical storms. Nat Geosci 6:534-539

Enfield DB, Nunez AMM, Trimble JP (2001) The Atlantic multidecadal oscillation and its relation to rainfall and river flows in the continental US. Geophys Res Lett 28:2077-2080

Folland CK, Parker DE, Palmer TN (1986) Sahel rainfall and worldwide sea temperatures, 1901-85. Nature 320:602-607

Gillett NP et al (2016) The Detection and Attribution Model Intercomparison Project (DAMIP v1.0) contribution to CMIP6. Geosci Model Dev 9:3685-3697

Goldenberg SB, Landsea CW, Nunez AMM, Gray WM (2001) The recent increase in Atlantic hurricane activity: causes and implications. Science 293:474-479

Griffies SM et al (2011) The GFDL CM3 coupled climate model: characteristics of the ocean and sea ice simulations. J Clim 24:3520-3544

Ishii M, Kimoto M (2009) Reevaluation of historical ocean heat content variations with time-varying XBT and MBT depth bias corrections. J Oceanogr 65:287-299
Kay JE et al (2015) The Community Earth System Model (CESM) large ensemble project: a community resource for studying climate change in the presence of internal climate variability. Bull Am Meteorol Soc 96:1333-1349

Keenlyside N, Latif M, Jungclaus J, Kornblueh L, Roeckner E (2008) Advancing decadal-scale climate prediction in the North Atlantic sector. Nature 453:84-88

Kerr RA (2000) A North Atlantic climate pacemaker for the centuries. Science 288:1984-1985

Knight JR, Folland CK, Scaife AA (2006) Climate impacts of the Atlantic Multidecadal Oscillation. Geophys Res Lett 33:L17706

Koch D et al (2011) Coupled aerosol-chemistry-climate twentieth-century transient model investigation: trends in short-lived species and climate responses. J Clim 4:2693-2714

Kushnir Y (1994) Interdecadal variations in North Atlantic sea surface temperature and associated atmospheric conditions. J Clim $7: 141-157$

Lohmann U, Feichter J (2005) Global indirect aerosol effects: a review. Atmos Chem Phys 5:715-737

Mahajan S, Zhang R, Delworth TL (2011) Impact of the Atlantic meridional overturning circulation (AMOC) on Arctic surface air temperature and sea ice variability. J Clim 24:6573-6581

Matei D et al (2012) Multiyear prediction of monthly mean Atlantic meridional overturning circulation at $26.5^{\circ} \mathrm{N}$. Science $335: 76-79$

Menary MB, Scaife AA (2014) Naturally forced multidecadal variability of the Atlantic meridional overturning circulation. Clim Dyn 42:1347-1362

Morice CP, Kennedy JJ, Rayner NA, Jones PD (2012) Quantifying uncertainties in global and regional temperature change using an ensemble of observational estimates: the HadCRUT4 dataset. J Geophys Res 117:D08101. https://doi.org/10.1029/2011JD017187

Murphy L, Bellomo K, Cane MA, Clement AC (2017) The role of historical forcings in simulating the observed Atlantic multidecadal oscillation. Geophys Res Lett 44:2472-2480

Neale RB et al (2010) Description of the NCAR community atmosphere model (CAM 4.0). NCAR technical note NCAR/TN-486+STR, National Center for Atmopsheric Research, Boulder, CO, 268

Otterå $\mathrm{OH}$, Bentsen M, Drange $\mathrm{H}$, Suo L (2010) External forcing as a metronome for Atlantic multidecadal variability. Nat Geosci 3:688-694

Robson J, Sutton R, Lohmann K, Smith D, Palmer MD (2012) Causes of the rapid warming of the North Atlantic Ocean in the mid1990s. J Clim 25:4116-4134

Robson J, Hodson D, Hawkins E, Sutton R (2014) Atlantic overturning in decline? Nat Geosci 7:2-3

Rotstayn LD et al (2010) Improved simulation of Australian climate and ENSO-related rainfall variability in a global climate model with an interactive aerosol treatment. Int J Climatol 30:1067-1088

Saravanan R, McWilliams JC (1998) Advective ocean-atmosphere interaction: an analytical stochastic model with implications for decadal variability. J Clim 11:165-188

Schlesinger ME, Ramankutty N (1994) An oscillation in the global climate system of period 65-70 years. Nature 367:723-726

Schneider U et al (2013) GPCC's new land surface precipitation climatology based on quality-controlled in situ data and its role in quantifying the global water cycle. Theor Appl Climatol 115:15-40

Shiogama $\mathrm{H}$ et al (2010) Possible influence of volcanic activity on the decadal potential predictability of the natural variability in near-term climate predictions. Adv Meteorol. https://doi. org/10.1155/2010/657318

Sobel AH, Nilsson J, Polvani LM (2001) The weak temperature gradient approximation and balanced tropical moisture waves. J Atmos Sci 58:3650-3665

Steinman BA, Mann ME, Miller SK (2015) Atlantic and Pacific multidecadal oscillations and Northern Hemisphere 
temperatures. Science 347:988-991. https://doi.org/10.5061/ dryad.6f576

Sutton RT, Dong B (2012) Atlantic Ocean influence on a shift in European climate in the 1990s. Nat Geosci 5:788-792

Sutton RT, Hodson DLR (2005) Atlantic Ocean forcing of North American and European summer climate. Science 309:115-118

Sutton RT, McCarthy GD, Robson J, Sinha B, Archibald AT, Gray LJ (2018) Atlantic multidecadal variability and the U.K. ACSIS program. Bull Am Meteorol Soc 99:415-425

Takahashi C, Watanabe M (2016) Pacific trade winds accelerated by aerosol forcing over the past two decades. Nat Clim Change 6:768-772. https://doi.org/10.1038/nclimate2996

Takemura $\mathrm{T}$ et al (2009) A simulation of the global distribution and radiative forcing of soil dust aerosols at the Last Glacial Maximum. Atmos Chem Phys 9:3061-3073

Tandon NF, Kushner PJ (2015) Does external forcing interfere with the AMOC's influence on North Atlantic sea surface temperature? J Clim 28:6309-6323. https://doi.org/10.1175/JCLI-D-14-00664.1

Taylor KE, Stouffer RJ, Meehl GA (2012) An overview of CMIP5 and the experiment design. Bull Am Meteorol Soc 93:485-498

Terray L (2012) Evidence for multiple drivers of North Atlantic multidecadal climate variability. Geophys Res Lett 39:L19712. https:// doi.org/10.1029/2012GL053046

Ting M, Kushnir Y, Seager R, Li C (2009) Forced and internal twentieth-century SST in the North Atlantic. J Clim 22:1469-1481

Undorf S, Bollasina MA, Booth BBB, Hegerl G (2018) Contrasting the effects of the 1850-1975 increase in sulphate aerosols from North America and Europe on the Atlantic in the CESM. Geophys Res Lett 45:11930-11940. https://doi.org/10.1029/2018GL079970

van Vuuren DP et al (2011) The representative concentration pathways: an overview. Clim Change 109:5-31

Vellinga M, Wu P (2004) Low-latitude freshwater influence on centennial variability of the Atlantic thermohaline circulation. J Clim $17: 4498-4511$ von Salzen K et al (2013) The Canadian fourth generation atmospheric global climate model (CanAM4). Part I: representation of physical processes. Atmos Ocean 51:104-125

Wang J, Yang B, Ljungqvist FC, Luterbacher J, Osborn TJ, Briffa KR, Zorita E (2017) Internal and external forcing of multidecadal Atlantic climate variability over the past 1,200 years. Nat Geosci 10:512-517. https://doi.org/10.1038/ngeo2962

Watanabe $\mathrm{M}$ et al (2010) Improved climate simulation by MIROC5: mean states, variability, and climate sensitivity. J Clim 23:6312-6335

Watanabe $\mathrm{M}$ et al (2014) Contribution of natural decadal variability to global-warming acceleration and hiatus. Nat Clim Change 4:893-897

Xie SP, Lu B, Xiang B (2013) Similar spatial patterns of climate responses to aerosol and greenhouse gas changes. Nat Geosci 6:828-832

Zhang R (2007) Anticorrelated multidecadal variations between surface and subsurface tropical North Atlantic. Geophys Res Lett 34:L12713. https://doi.org/10.1029/2007GL030225

Zhang R, Delworth TL (2006) Impact of Atlantic multidecadal oscillations on India/Sahel rainfall and Atlantic hurricanes. Geophys Res Lett 33:L17712

Zhang L, Wang C (2013) Multidecadal North Atlantic sea surface temperature and Atlantic meridional overturning circulation variability in CMIP5 historical simulations. J Geophys Res 118:5772-5791

Zhang R et al (2013) Have aerosols caused the observed Atlantic multidecadal variability? J Atmos Sci 70:1135-1144

Publisher's Note Springer Nature remains neutral with regard to jurisdictional claims in published maps and institutional affiliations. 